\title{
Sound emmeshes for aircraft bird collision prevention
}

\begin{abstract}
As Airliners and Airlines increased over the turn of the century, so did Aircraft crashes primarily due to Bird hitting the engines. It has been surveyed that over $44 \%$ of Deaths caused in Aircraft crashes are due to Bird collisions. That's a horrifying figure, if we consider the increasing number of deaths caused each year due to aircraft crashes. Bird hitting aircraft engines also causes incredible damage in addition to loss of life. It is estimated that bird collisions cost the global airline industry well over 2 Billion Dollars. This remarkable figure is mainly because of some of the irreplaceable damage the collisions or strikes by birds cause to the aircraft. Because of so much damage and loss of life caused by Flocks of Birds and Bats, Its Imperative that we minimize such loses. The pressing need is due to the increasing number of reports of aircraft crash accidents due to bird strikes year after year. Although it can be argued that this may be due to better reporting and advanced technologies for observing such accidents, one cannot ignore the rise in frequency of such accidents.
\end{abstract}

Volume 2 Issue 2 - 2018

\author{
Vinayak Malhotra \\ Department of Aerospace Engineering, SRM University, India
}

Correspondence: Vinayak Malhotra, Department of Aerospace Engineering, SRM University, Chennai, India, Tel 09840599069, Email vinn99@gmail.com

Received: August 15, 2017 | Published: March 12, 2018

\section{Introduction}

In 2007 there were about 600 bird strike accidents reported worldwide. In 2014 that number has nearly doubled to about 1400 bird strike accidents. In recently, bird hitting in aircrafts have grown at an alarming rate resulting in severe losses (Figure 1). The possibility of bird or flock of birds hitting an aircraft is a global issue and have been a potential source of irreplaceable damages financially, to human resources, ecologically. An instinctive idea would understand the consequence of bird striking planes. It had been reported that for an aircraft flying at $600 \mathrm{mph}$, the impact would be around 12 Tons. Appreciable efforts have/had been undertaken ${ }^{1-8}$ and every year huge amount of money is spent to control these accidents however, the complexity of the problem has prevented a thorough understanding. This has necessitated active research efforts on the need to minimize the bird aircrafts collisions so that precious human life and property can be saved in addition to tens of millions of dollars being saved thus.
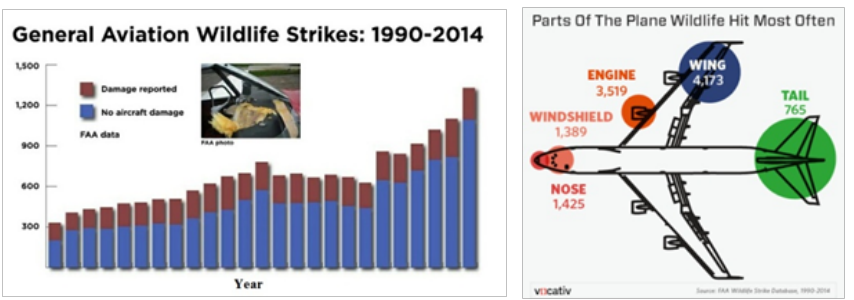

Figure I Reported bird strikes and parts mostly hit (* FAA wildlife strike data base).

\section{Sound and mesh coupling}

An important aspect which possibly can explain potential mitigation to solve the above pressing issues is application of state of the art hands-off - hands-on approach. Which details to utilization of two potential prevention sources with alternated operations? A possible approach can be utilization of integrated meshes with concentrated sound systems. In the present proposal, synthesized composite wire meshes are placed before aircraft inlets and windscreen for prevention of bird disturbing engine functioning. Integrated wire mesh working is digitally operated by the pilot and can be made to open and close if the bird or a flock of birds is in the vicinity. This is made possible by continuously monitoring lumped disturbances relative to that of the aircraft with the help of sensors. Meshes are made to open and close in highly anticipated regions of bird or flock of birds and are flexible enough to be removed when not needed viz., during cruise. The mesh is designed to close around the engines opening only during takeoff, ascent, approach, landing. This is very much feasible because $96 \%$ of the bird strike incidents occur only in the above mentioned four zones. Hence, the mesh can be made to open out once the aircraft reaches a higher altitude (Alt $>5000 \mathrm{ft}$ ). At this height except for eagles and vultures, the chances of birds hitting aircrafts becomes incredibly low. It is important to note that the integrated meshes account the minimum disturbance to engine functioning and performance viz., undisturbed mass flow rate under all conditions. Emphasis is laid on the advanced materials to be used for manufacturing meshes to withstand diverse conditions of aircraft operations. With adaptation of meshes for preventing aircrafts alongside, well concentrated sound incorporation device is fitted with a sensor which senses incoming birds and can warn birds by means of a sound set in a certain frequency which can ward them off ultimately. Sounds of varying frequency have been widely known to affect significantly. Meshes and sound are used alternatively and simultaneously as per the requirement. The utilization of sound minimizes the ecological loss by diverting attention of birds approaching. This can go a long way in preventing accidents. Similar to the automobile industry, the substantiation of sound with integrated meshes will prove as a boon for bird hitting mitigation. Key controlling parameter viz., location of sound source, frequency, intensity is subjected to vary for different aircrafts. The contribution of the proposal is likely to be very rewarding. It can almost minimize every possible damage caused to the aircraft; prevent hundreds of such accidents, ultimately saving life and money. 


\section{Acknowledgement}

None.

\section{Conflict of interest}

None.

\section{References}

1. Layborne RC. Collision Between a Vulture and an Aircraft at an Altitude of 37,000 feet. Wilson Bulletin. 1974;86(4):461-462.

2. Chilvers BL, Christine JR, Graham JH. Factors affecting pilot-reported bird-strike rates at Christchurch International Airport, New Zealand. New Zealand Journal of Zoology. 1997;24:1-7.

3. Brown J, Hickling G. The problems of analysis of pilot-reported birdstrikes as an index for actual bird-strikes at airports. New Zealand Journal of Zoology. 2000;27:45-47.
4. Dolbeer RA. Height Distribution of Birds Recorded by Collisions with Civil Aircraft. Journal of Wildlife Management. 2006;70(5):1345-1350.

5. Dolbeer RA. Increasing trend of damaging bird strikes with aircraft outside the airport boundary: implications for mitigation measures. Human-Wildlife Interactions. 2011;5(2):235-248.

6. International Civil Aviation Organization. Annex 13-Aircraft accident and incident investigation. $10^{\text {th }}$ edn. Canada: ICAO; 2010.

7. Martin GR. Understanding Bird Collisions with Man-Made Objects: a Sensory Ecology Approach. The International Journal of Avian Science. 2011;153(2):239-254.

8. Thorpe J. 100 years of fatalities and destroyed civil aircraft due to bird strikes. 30th Meeting of the International Bird-strike Conference; 2012 June 25-29; Stavanger, Norway. 